\title{
Numerical simulations of cone penetration in cemented sandstone
}

\author{
Aigerim Rakhimzhanova ${ }^{1 *}$, Colin Thornton ${ }^{2}$, Yerlan Amanbek ${ }^{1}$ and Yong Zhao ${ }^{1}$ \\ ${ }^{1}$ Nazarbayev University, Nur-Sultan 010000, Kazakhstan \\ ${ }^{2}$ Private Consultant, colinthornton18@gmail.com
}

\begin{abstract}
In this study, three-dimensional simulations of cone penetration tests (CPT) in cemented sandstone have been investigated using the Discrete Element Method (DEM). We generated the realistic grain size distribution of sandstone in the numerical simulations using the Ustyurt-Buzachi Sedimentary Basin samples. Numbers of numerical CPT tests at different bond strength values were performed with the penetrometer vertically moved down at a constant rate. The results of the real-world particle size distribution show that the cone penetration resistance and side friction increase with increasing depths; and with increase in bond strength the cone resistance and side friction decrease, while the friction ratio increases. The result of numerical CPT tests in cemented sandstone was found to be in good agreement with the Soil Behaviour Type (SBT) classification system from CPT data.
\end{abstract}

\section{Introduction}

The main applications of the cone penetration test (CPT) in geotechnical engineering are for classification and identification of soil types, and for stratigraphic profiling. In a field cone penetration test, a cone with its sleeve is moved down into the ground, where the cone resistance is the force required pushing the tip of the cone and the friction sleeve is the force required to push the sleeve through the ground. Then the friction ratio is calculated by the ratio between sleeve friction and cone penetration resistance. The classification of soil type can be identified from such basic CPT data.

Here, we provide a brief summary of the literature relating to the cone penetration test in granular soils that has been numerically investigated using the $2 \mathrm{D}$ and $3 \mathrm{D}$ Discrete Element Method [1]: mechanisms of deep [2, 3] and inclined [4] CPT tests in granular soils (in 2D); 2D CPT tests under different gravity conditions [5] and 3D CPT tests in a calibration chamber [6-10] taking into account the particle crushing behaviour; and 3D DEM simulations of CPT tests in sand material [11], where authors used the up-scaled Ottawa 20-30 sand and interpreted the response of the material as coarse-grained soils using the Soil Behaviour Type (SBT) charts.

The main aim of this study is to investigate threedimensional DEM simulations of cone penetration tests in weakly cemented sandstone using the real-world particle size distribution and periodic boundaries and to examine the effect of cementation bond strength. This research applies the recent development of a simple 3D bond contact model for cemented sandstone material [1213]. Further, interpretation of obtained realistic cone

\footnotetext{
* Corresponding author: aigerim.rakhimzhanova@nu.edu.kz

A video is available at https://doi.org/10.48448/4j16-em95
}

resistance and side friction results within the CPT based SBT classification system [14].

\section{Numerical simulations}

In all simulations, particles are considered to be elastic and frictional, where the particle-particle and wallparticle contact forces without adhesion are calculated using the theories of Hertz [15] to determine the normal force, and Mindlin [16] to calculate the tangential interaction force. A simple 3D bond contact model for cemented sandstone material [12-13] was used to calculate the interparticle normal contact force with adhesion, which simply modified the existing JKR model for auto-adhesive silt sized particles [17, 18], and no-slip model [16] to calculate the tangential interaction force.

In this study, the cone penetration tests have four stages: particle generation, pluvial deposition, compression, cone penetration (see Fig. 2). Threedimensional DEM simulations of cone penetration tests have been performed using 10000 frictional elastic spheres bonded together over a range of bond strengths (interface energy of adhesion) of $\Gamma=0,5,10,20 \mathrm{~J} / \mathrm{m}^{2}$ (where $\Gamma=0 \mathrm{~J} / \mathrm{m}^{2}$ is an uncemented sample) and compressed at $1 \mathrm{MPa}$ of overburden pressure, wherein all cases particle rotations were prevented.

\subsection{Particle generation and deposition}

In this study, the same eight different sand grain sizes and material properties [12-13] were reused for the CPT test simulations, where the grain sizes were initially selected from the Qicpic dynamics image analyzer measurements from [19] for the Ustyurt-Buzachi Sedimentary Basin 
samples (Fig. 1). Particles were randomly generated (Fig. 2a) within a thin rectangular parallelepiped of dimension $8.4 \mathrm{~mm}$ in width, $21 \mathrm{~mm}$ in height and $1.4 \mathrm{~mm}$ in thickness: $0.355 \mathrm{~mm}$ (306), $0.3 \mathrm{~mm}$ (610), $0.275 \mathrm{~mm}$ (1119), $0.25 \mathrm{~mm}$ (1973), $0.22 \mathrm{~mm}$ (1558), $0.2 \mathrm{~mm}$ (1505), $0.18 \mathrm{~mm}$ (1750), and $0.15 \mathrm{~mm}$ (1179).

On the basis of the Unified Soil Classification System (USCS) [20] these grain sizes pass through the sieve sizes \#45-100, which indicates that the soil type is $\mathrm{S}$ - sand with the subdivision of fine sand. The thin parallelepiped workspace was divided into 720 small DEM boxes (box dimension of $0.0007 \mathrm{~mm}$ ): 12 boxes in width, 30 in height and 2 in thickness. The following material properties were used for all sand particles: experimental particle density $\rho=2605 \mathrm{~kg} / \mathrm{m}^{3}$, Poisson ratio $v=0.3$ and Young's modulus $E=70 \mathrm{GPa}$. Further, a vertical gravity field was applied to the system and all particles were pluvially deposited to form the initial homogeneous bed (Fig. 2b). One finite wall was created at the base of workspace that one may avoid/prevent the periodic boundary condition at this side. The following material properties of iron were used for all walls: density $\rho=7$ $900 \mathrm{~kg} / \mathrm{m}^{3}$, Poisson ratio $v=0.29$ and Young's modulus $E=210 \mathrm{GPa}$.

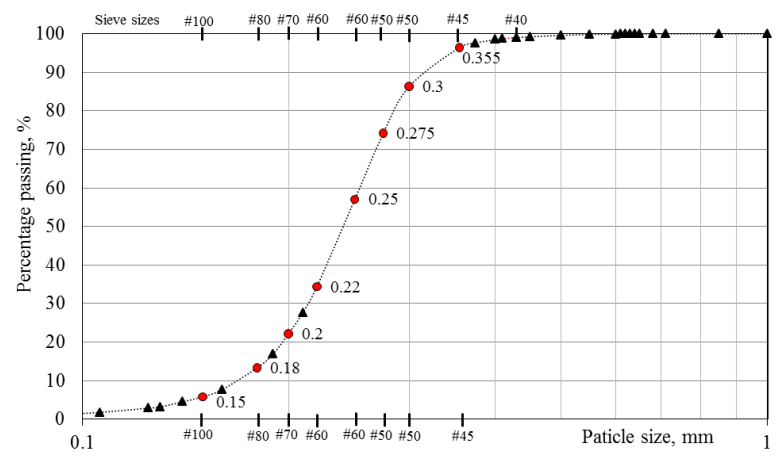

Fig. 1. Grain size distribution

\subsection{Compression and cone penetration}

Three top finite walls were created at the top of the deposited specimen and pushed down at a wall velocity of $0.1 \mathrm{~m} / \mathrm{s}$ to vertically compress the sample (Fig. 2c). When a vertical stress level (overburden pressure) reached $500 \mathrm{kPa}$, then the bond strength values $\Gamma=0,5$, $10,20 \mathrm{~J} / \mathrm{m}^{2}$ were set. When the overburden pressure reached $1 \mathrm{MPa}$, the top three wall velocities were reset to 0 . After the compression of DEM cemented sandstone, a cone penetrometer was created just above the compressed bed and then pushed down at a high constant rate of $0.1 \mathrm{~m} / \mathrm{s}$ in order to avoid computational cost. The penetrometer had a "radius" $R$ of $0.7 \mathrm{~mm}$ and an apex angle of $60^{\circ}$ (Fig. 2d). It was defined as 2 rigid frictional walls inclined to $x$-axis at $60^{\circ}$ to simulate the cone/tip penetrometer and two rigid vertical frictional walls to simulate the penetrometer sleeve (Fig. 3). During the simulations the cone was always in contact with around 33-35 particles, which give the resistance value. The surface of initial ground is treated as the origin and the distance between the tip point (lowest point of tip) and the origin is defined as the penetration depth $y$. The cone penetrometer was removed from the penetrated specimen once the cone tip had reached $2 / 3$ of the depth.

\section{Numerical results}

Fig. 4a, Fig. 4b and Fig. 4c show the evolution of cone resistance, friction sleeve and friction ratio data at different penetration depths for $\Gamma=0,5,10,20 \mathrm{~J} / \mathrm{m}^{2}$, respectively. The cone resistance is defined as the vertical pressure measured on the cone

$$
q_{c}=\frac{\sum f_{y}}{2 R t}
$$

where $f_{y}$ is the contact force vertically acting on inclined wall (cone); $R$ is the cone radius; $t$ is the thickness of the bed $(t=2 R)$, and the frictional sleeve, $f_{s}$, is defined as

$$
f_{s}=\frac{\sum f_{y}}{2 H t}
$$

where $f_{y}$ is the vertically acting contact force on the sleeve friction; $H$ is the frictional sleeve height in the ground.

It can be seen that the cone penetration resistance and friction sleeve increase with increasing depths. Similar behavior was numerically obtained by $[2,3]$, and in the real field CPT data [21].

The friction ratio, $R_{f}$, is calculated as

$$
R_{f}=\frac{f_{s}}{q_{c}} \cdot 100 \%
$$

where $q_{c}$ is from Eq. (1) and $f_{s}$ from Eq. (2). The results show that the cone resistance and side friction decrease with increase in bond strength.

The decrease of cone resistance with increase in bond strength is believed to be caused by bond breakage during penetration process. The previous study shows $[12,13]$ that more bond breakage occurs for a lower bond strength values of lightly cemented sandstone $(\Gamma=5,10$ and 20 $\mathrm{J} / \mathrm{m} 2$ ) and it leads to rearrangement/displacement of damaged particles. This results in a change in the number of contacts (Fig. 4d) and mechanical average coordination numbers (Fig. 4e).

The initial number of contacts (start and end of penetration) increased from 23804 to 30814 (29.45\%), from 24075 to 30821 (28.02\%), from 23987 to 30713 (28.04\%), from 23683 to $30473(28.67 \%$ ) for bond strength values $\Gamma=0,5,10$ and $20 \mathrm{~J} / \mathrm{m} 2$, respectively. The mechanical average coordination number increased from 5.33 to $6.373(19.57 \%)$, from 5.347 to 6.392 (19.54 $\%)$, from 5.322 to $6.353(19.37 \%)$, from 5.29 to 6.302 $(19.13 \%)$ for bond strength values $\Gamma=0,5,10$ and 20 $\mathrm{J} / \mathrm{m} 2$, respectively. Fig. $4 \mathrm{~d}$ shows that the total number of contacts increases with decrease in bond strength and for $\Gamma>0$, the number of contacts initially decreases due to the breaking of bonds but then the total number of contacts (both bonded and unbonded new contacts) increases (consistent with the previous study $[12,13]$ ).

More contacts between the sand grains result in a high mechanical average coordination number. This high number of contacts and/or mechanical average coordination numbers may create a strong force network and transmit the applied force from the cone and sides of the penetrometer as it was observed by Butlanska et al. $[8,9]$. 

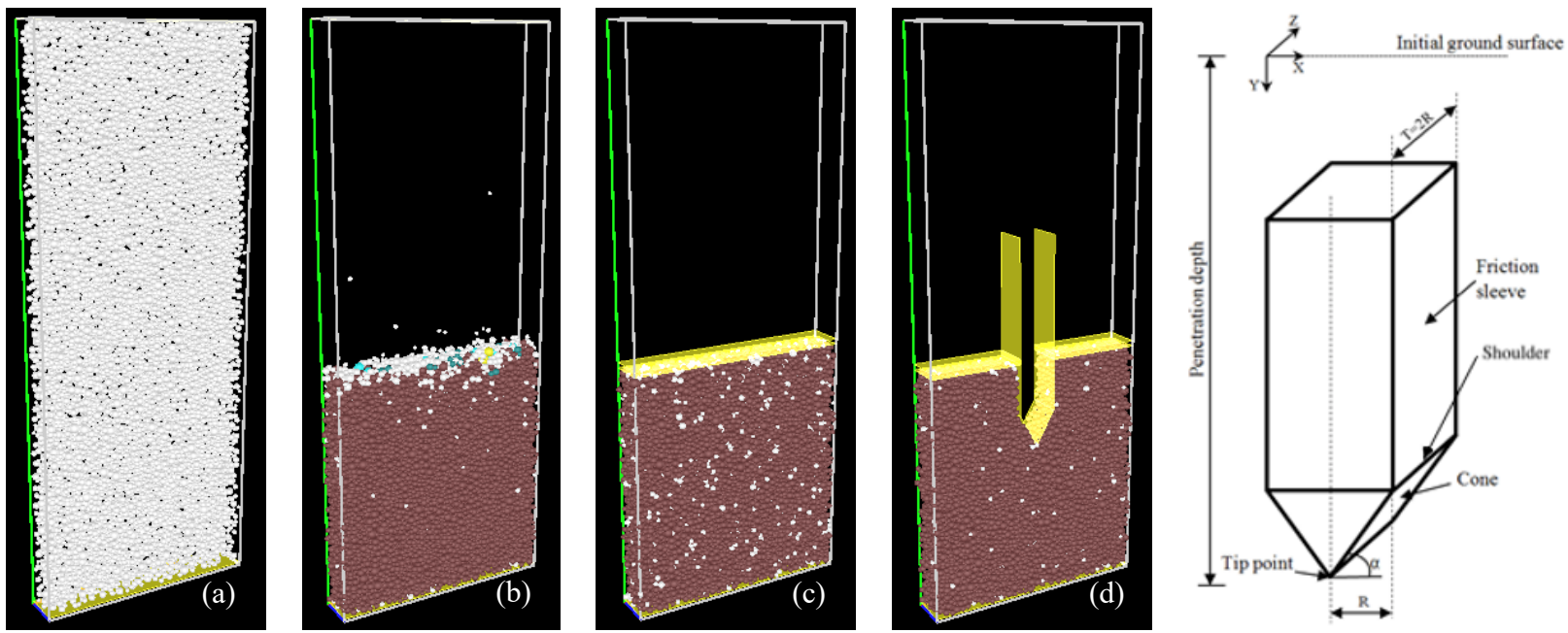

Fig. 2. 3D DEM cone penetration simulation stages: (a) particle generation; (b) pluvial deposition; (c) compression; (d) cone penetration. (the different colors indicate the cluster size: white particles have one particle in one cluster; light cyan -2 ; dark cyan -3 ; light yellow - 4; dark cyan - 5; magenta -10; green -50; brown - more than 2000 particles)

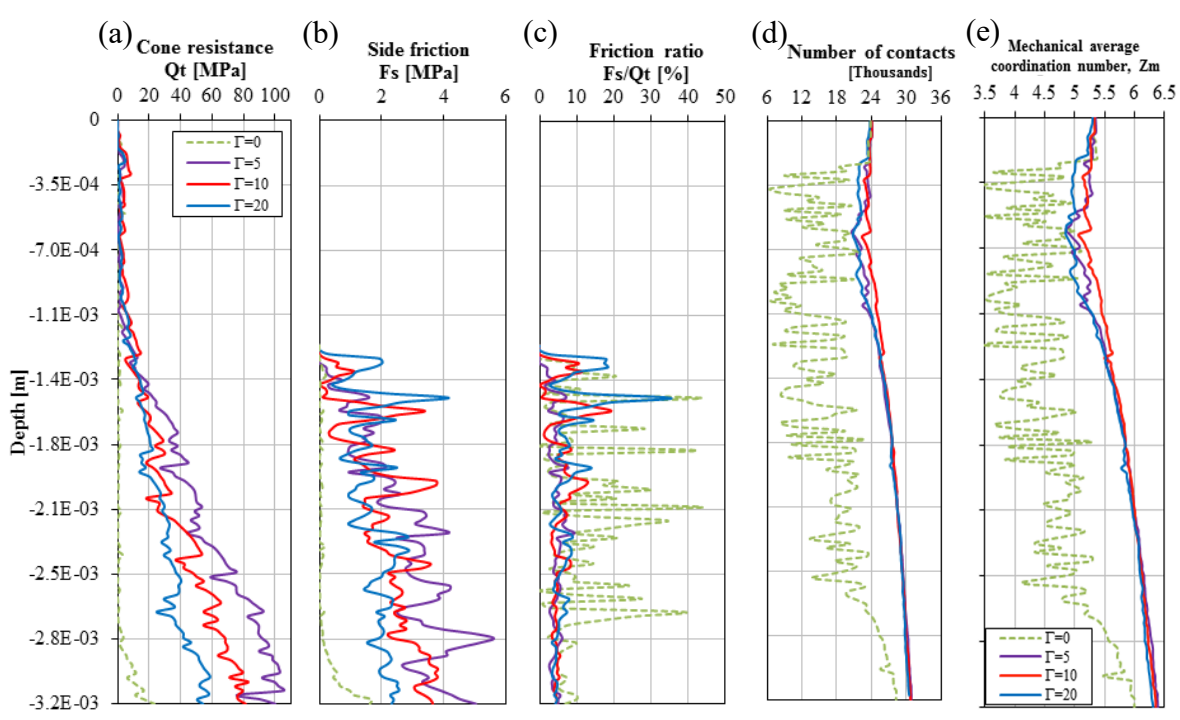

Fig. 3. Cone penetrometer (modified from [3]).

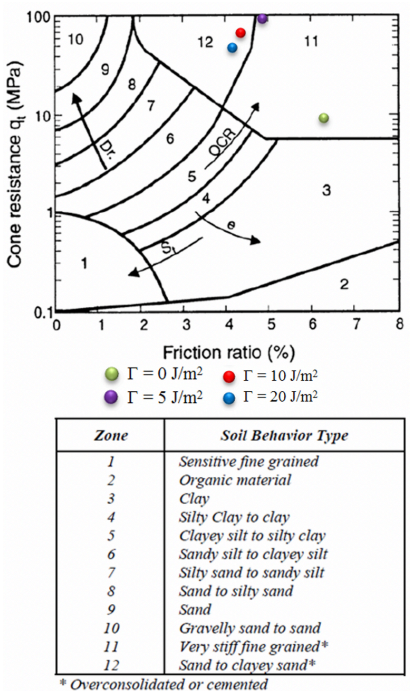

Fig. 5. SBT classification system from CPT data [13])

Fig. 4. CPT data: (a) cone resistance; (b) side friction; (c) friction ratio; (d) number of contacts; (e) mechanical average coordination number

Further, the SBT classification system chart based on the basic field CPT data $[14,21]$ is used, where only the total cone penetration resistance, $q_{t}$, and the sleeve friction, $f_{c}$, are available (Fig. 5). The resistance of cone can be corrected to the total resistance of cone [22] as

$$
q_{t}=q_{c}+u(1-a)
$$

where $u$ is the pore pressure measured between the tip of cone and the sleeve friction and $a$ is the net area ratio calculated as $a=d^{2} / D^{2}$, where $D$ is the cone diameter and $d$ is the sleeve friction diameter. This correction should be made to account for unequal end area effects because the water pressure acts on an area immediately behind the cone tip. Since the numerical simulations of cone penetration tests conducted on dry particles the net area, $a$, was equal to 1 and the assumption of $q_{c}=q_{t}$ has been made.

The data points of DEM simulations of CPT tests in cemented sandstone have been added in this classical soil classification chart. The average values of cone resistance and friction sleeve were taken starting from the depth $2.5 \mathrm{~mm}$, once they became more stable. It is shown that the CPT data of samples with higher bond strengths of $\Gamma=10$ and $20 \mathrm{~J} / \mathrm{m}^{2}$ locates in SBT zone 12, which is identified as overconsolidated or cemented sand to clayey sand; and $\Gamma=0$ and $5 \mathrm{~J} / \mathrm{m}^{2}$ locate in SBT zone 11, which behaves as very stiff, overconsolidated finegrained sand.

At the end of the compression stage, the material that contains only fine sand particles (Fig. 1) had a porosity of about 0.38 , which is similar to those porosities obtained for 3D DEM simulations of triaxial shear tests of cemented sandstone on medium dense samples compressed at $1 \mathrm{MPa}$ and $\Gamma=0,5,10,20 \mathrm{~J} / \mathrm{m}^{2}$ [13]. This may explain the location of data points for all samples at SBT zones 11 and 12.

For $\Gamma=5 \mathrm{~J} / \mathrm{m}^{2}$ it can be explained that, at the lowest value of $\Gamma=5 \mathrm{~J} / \mathrm{m}^{2}$, the bond strength is soft, and more bonds were broken, compared with higher values of $\Gamma=$ 10 and $20 \mathrm{~J} / \mathrm{m}^{2}$, with a tendency to behave like the uncemented sand. The SBT zone 11 for uncemented sand $\left(\Gamma=0 \mathrm{~J} / \mathrm{m}^{2}\right)$ can be explained in that with an increase in 
initial density and/or confining pressure the sand becomes stiffer (frictional response). Similar behavior has been experimentally [23] and numerically [12-13] obtained for the compressive behavior of fine sand.

\section{Concluding remarks}

In this paper, the previously developed 3D bond contact model for bonded granular material has been used to simulate the 3D DEM simulations of cone penetration test in weakly cemented sandstone. Material properties and real-world grain size distribution of reservoir equivalent sandstone from the Ustyurt-Buzachi Sedimentary Basin samples were reproduced for the numerical experiments. The bond strength values that were previously identified and verified with experimental results [12-13] were used for the simulations of CPT test. The effect of different cementation bond strength has been studied.

The results show that the cone resistance and side friction increase with an increase in penetration depths and with decrease in bond strength. Due to bond breakage, the lower values of bond strength have higher mechanical average coordination number and number of contacts (particle-particle and wall-particle) and it may cause an increase of cone resistance and side friction in weakly/lightly cemented sandstone material. In addition, the number of contacts between penetrometer wall and particles plays an important role, since only limited number of particles is in contact with inclined (cone) and vertical (sleeve) walls. Consequently, the contact force $\left(f_{y}\right)$ vertically acing on cone and side walls may increase with increase in particle-wall contact number during penetration process.

It has been demonstrated that the numerical CPT tests result of cemented sandstone are in good agreement with the Soil Behavior Type (SBT) classification system from CPT data. The findings suggest that this method could also be helpful for practicing engineers to control the perforation technique in the sandstone field.

\section{Acknowledgments}

This research was supported by the HERCULES "towards geoHazards rEsilient infRastruCtUre under changing cLimatES" (Grant No 778360), the Ministry of Education and Science of the Republic of Kazakhstan (Grant No AP08052762), the Nazarbayev University Faculty Development Competitive Research (Grant No 110119FD4502). The authors gratefully acknowledge Prof. Stefano Utili (Newcastle University) and Dr. Helen Cheng (University College London) for their help during the first author's visits to the UK.

\section{References}

[1] P.A. Cundall and O.D.L. Strack, Geotechnique 29, 47 (1979)

[2] A.B. Huang and M.Y. Ma, Can. Geotech. J. 31, 91 (1994)

[3] M.J. Jiang, H.S. Yu, D. Harris, Int. J. Numer. Anal. Meth. Geomech. 30, 335 (2006)
[4] M.J. Jiang, Y. Dai, L. Cui, Z. Shen, X. Wang, Granul. Matter 16, 785 (2014)

[5] M.J. Jiang, F. Liu, H. Wang, X. Wang, Eng. Comput. 32, 2067 (2015)

[6] M. Arroyo, J. Butlanska, A. Gens, F. Calvetti, M. Jamiolkowski, Géotechnique 61, 525 (2011)

[7] J. Butlanska, M. Arroyo, A. Gens, Virtual calibration chamber CPT on Ticino sand, in $2^{\text {nd }}$ Int. Symposium on Cone Penetration Testing, Huntington Beach, CA, USA (2010)

[8] J. Butlanska, M. Arroyo, A. Gens, C. O'Sullivan, Can. Geotech. J. 51, 51 (2014)

[9] J. Butlanska, Cone penetration test in a virtual calibration chamber. Doctoral thesis, Universitat Politècnica de Catalunya, 2014.

[10] M.O. Ciantia, M. Arroyo, J. Butlanska, A. Gens, Comput. Geotech. 73, 109 (2016)

[11] A. Khosravi, A. Martinez, J.T. DeJong, Can. Geotech. J. 57, 1369 (2019)

[12] A.K. Rakhimzhanova, F.A. Khamitov, N.H. Minh, C. Thornton, 3D DEM simulations of triaxial compression tests of cemented sandstone, in Proceedings of IS Atlanta 2018 symposium on geomechanics from micro to macro in research and practice, Atlanta, USA (2018) (in press)

[13] A.K. Rakhimzhanova, C. Thornton, N.H. Minh, S.C. Fok, Y. Zhao, Comput. Geotech. 113, 103068 (2019)

[14] P.K. Robertson, R.G. Campanella, D. Gillespie, J. Greig, Use of piezometer cone data, in Use of in situ tests in geotechnical engineering, June 23, ASCE (1986)

[15] H. Hertz, J. für die Reine und Angew. Math. 92, $156(1881)$

[16] R.D. Mindlin, Trans. ASME J. Appl. Mech. 16, 259 (1949)

[17] K.L. Johnson, K. Kendall, A.D. Roberts, Proc. R. Soc. Lond. A. 324, 301 (1971)

[18] K.L. Johnson, Adhesion at the contact of solids, in Proceedings of the 4th IUTAM Congress, 133 (1976)

[19] A.D. Shabdirova, Z. Bissekenova, N.H. Minh, J.R. Kim, Sample preparation method of clay-rich sandstone analogue of sandstone reservoirs in Kazakhstan, in 50th US Rock Mechanics / Geomechanics Symposium (2016)

[20] USGS Open-File Report 2006-1195. https://pubs.usgs.gov/of/2006/1195/htmldocs/imag es/chart.pdf

[21] P.K. Robertson, Can. Geotech. J. 27, 15 (1990)

[22] R. Campanella, P. Robertson, State-of-the-art in insitu testing of soils; developments since 1978, engineering, in Foundation Conference on Updating Subsurface Sampling of Soils and Rocks and Their In-Situ Testing (1982)

[23] M.E. Kabir, B. Song, B.E. Martin, W. Chen, Compressive behaviour of fine sand. Sandia National Laboratories (2010) 